\title{
O marco sanitário na alimentação escolar: um estudo dos agricultores participantes do PNAE em Ladainha/MG
}

\author{
The health milestone in school feeding: a study of farmers participation in the PNAE in \\ Ladainha/MG \\ Mariane Rodrigues Silva" ${ }^{*}$, Nadja Maria Gomes Murta \\ Universidade Federal dos Vales do Jequitinhonha e Mucuri, Diamantina, Minas Gerais, Brasil. *Autor para \\ correspondência. E-mail: marimariane98@hotmail.com
}

\begin{abstract}
Resumo: Este trabalho apresenta parte dos estudos referentes à dissertação de mestrado em Estudos Rurais da Universidade Federal dos Vales do Jequitinhonha e Mucuri (UFVJM). Adotou por metodologia a Análise de Conteúdo de entrevistas realizadas com agricultores familiares participantes do Programa Nacional de Alimentação Escolar (PNAE) no município de Ladainha MG. Buscamos refletir sobre os desafios apontados pelos agricultores sobre a adequação sanitária dos seus sistemas produtivos para a comercialização junto ao PNAE, que por meio da Lei $n^{\circ}$ 11.947/2009 determinou a aquisição de gêneros alimentícios produzidos pela agricultura familiar local na alimentação escolar. Considerando que esta política para além da garantia da segurança alimentar nas escolas, abarca o fomento da agricultura familiar, foi preciso que os agricultores se atentassem aos critérios dispostos na Resolução/RDC $\mathrm{n}^{\circ} 49 / 2013$ que regulamenta o exercício da atividade de interesse sanitário do microempreendedor individual, do empreendimento familiar rural e empreendimento econômico solidário. Tal resolução passou a valer no âmbito do PNAE a partir do ano de 2013, impactando agricultores que já comercializavam para as escolas via PNAE desde o ano de 2009 através da Lei $n^{\circ} 11.947$. O presente trabalho visa contribuir na discussão acerca dos impactos que este marco sanitário vem acarretando na (não) participação dos agricultores familiares no PNAE em Ladainha MG.
\end{abstract}

Palavras-chave: habilitação sanitária, agricultura familiar, segurança alimentar, análise de conteúdo.

\begin{abstract}
This work presents part of the studies related to the Master's thesis in Rural Studies at the Federal University of Vales do Jequitinhonha and Mucuri (UFVJM). The methodology adopted was Content Analysis of interviews conducted with family farmers participating in the National School Feeding Program (PNAE) in the municipality of Ladainha MG. We seek to reflect on the challenges pointed out by farmers on the health adequacy of their production systems for commercialization with the PNAE, which, through Law No. 11,947 / 2009, determined the acquisition of foodstuffs produced by local family farming in school meals. Considering that this policy, in addition to guaranteeing food security in schools, encompasses the promotion of family farming, it was necessary for farmers to pay attention to the criteria set out in Resolution / RDC $n{ }^{\circ} 49 / 2013$ that regulates the exercise of the activity of health interest of the individual microentrepreneur, rural family enterprise and economic solidarity enterprise. Such a resolution became effective in the scope of the PNAE from the year 2013, impacting farmers who already marketed to schools via PNAE since the year 2009 through Law No. 11,947 . The present work aims to contribute to the discussion about the impacts that this health framework has been causing in the (non) participation of family farmers in the PNAE in Ladainha MG.
\end{abstract}

Keywords: sanitation, family farming, food security, content analysis.

\section{Introdução}

Nos últimos anos, o Brasil avançou de maneira significativa para com a priorização da alimentação escolar em toda a rede pública de ensino, institucionalizando nas políticas públicas as ações que buscam a promoção da Segurança Alimentar e Nutricional. Por meio do Programa Nacional de Alimentação Escolar (PNAE), a oferta da alimentação escolar qualificada vem sendo possibilitada graças à integração e incentivo da agricultura familiar e seus empreendimentos, que passam a ter neste programa o fomento à produção, bem como um novo canal de comercialização institucional.

Com relação ao histórico da alimentação escolar no Brasil, a legislação sanitária por muitos anos manteve a agricultura familiar marginalizada em detrimento dos produtos industrializados/processados, 
favorecendo o setor privado (indústria) na compra de alimentos para os escolares. Na atualidade, buscando promover a inclusão produtiva com segurança sanitária, foi lançada a Resolução/RDC nº49/2013, na qual o objetivo foi dispor de um instrumento normativo para o licenciamento de sistemas produtivos do microempreendedor individual, do empreendimento familiar rural e do empreendimento econômico solidário (BRASIL, 2013).

Para os agricultores familiares que produzem e comercializam ao PNAE por meio de agroindústrias ou empreendimentos familiares rurais ou econômicos solidários, é preciso se ater as obrigatoriedades da Resolução/RDC nº $49 / 2013$, que versará sobre os requisitos para a habilitação sanitária dos sistemas produtivos.

O presente artigo busca problematizar como se dá efetivamente o processo de habilitação sanitária dos agricultores familiares para o atendimento ao PNAE em Ladainha MG. Para tanto, consiste em um recorte dos resultados obtidos em uma pesquisa para a elaboração da dissertação de mestrado intitulada: "As percepções dos Agricultores Familiares do Município de Ladainha MG acerca do Programa Nacional de Alimentação Escolar - Uma análise de conteúdo", na qual será apresentada a discussão da categoria de análise "A adequação Sanitária dos sistemas produtivos para o atendimento ao PNAE em Ladainha MG".

\section{O PNAE e a incorporação da agricultura familiar na perspectiva do marco sanitário}

A agricultura familiar cumpre papel relevante na produção alimentar no Brasil e no mundo. A inclusão desta categoria em políticas públicas como o PNAE vem demonstrando o comprometimento em cumprir as diretrizes estruturantes do programa de promover o direito e o acesso a uma alimentação adequada no ambiente escolar introduzindo nos cardápios, os alimentos produzidos localmente, fortalecendo os hábitos alimentares culturais e o fomento da agricultura familiar, conforme art. $2^{\circ}$, incisos I; V; VI da Lei 11.947/2009:

I - o emprego da alimentação saudável e adequada, compreendendo o uso de alimentos variados, seguros, que respeitem a cultura, as tradições e os hábitos alimentares saudáveis, contribuindo para o crescimento e o desenvolvimento dos alunos e para a melhoria do rendimento escolar, em conformidade com a sua faixa etária e seu estado de saúde, inclusive dos que necessitam de atenção específica;

V - o apoio ao desenvolvimento sustentável, com incentivos para a aquisição de gêneros alimentícios diversificados, produzidos em âmbito local e preferencialmente pela agricultura familiar e pelos empreendedores familiares rurais, priorizando as comunidades tradicionais indígenas e de remanescentes de quilombos;

VI - o direito à alimentação escolar, visando a garantir segurança alimentar e nutricional dos alunos, com acesso de forma igualitária, respeitando as diferenças biológicas entre idades e condições de saúde dos alunos que necessitem de atenção específica e aqueles que se encontram em vulnerabilidade social (BRASIL, 2009).

Pode-se afirmar que o encontro da alimentação escolar com a agricultura familiar se deu efetivamente quando a Lei $\mathrm{n}^{\circ} 11.947$ de 2009 determinou em seu art.14 ${ }^{\circ}$ que do total dos recursos repassados pelo Fundo Nacional de Desenvolvimento da Educação (FNDE) para a alimentação escolar, ao menos 30\% (trinta por cento) deveriam ser destinados na compra direta de gêneros alimentícios produzidos pelo agricultor familiar, do empreendedor familiar rural ou de suas organizações (cooperativas e/ou associações), priorizando-se os assentamentos da reforma agrária, as comunidades tradicionais indígenas e quilombolas (BRASIL, 2009).

Neste sentido, cabe ressaltar que a reestruturação do PNAE por meio da Lei $n^{\circ}$ 11.947/2009 garantiu aos agricultores familiares "uma via de acesso a mercados institucionais, oferecendo-lhes oportunidade de comercialização" (SANTOS, 2017, p. 51) ao passo que também promoveu mudanças em como a alimentação passou a ser tratada no âmbito educacional, ou seja, alimentação enquanto algo que ultrapassa os limites do valor nutricional e da saúde, considerando também a dimensão cultural e social.

Mas a Resolução/RDC nº $49 / 2013$ foi além ao tratar da inclusão produtiva com segurança sanitária dos sistemas produtivos no âmbito do programa. É o que os autores Wagner e Gehlen (2015) consideram como uma série de pré-requisitos estabelecidos no âmbito do PNAE na qual podemos incluir a certificação de inspeção sanitária. 
[...] essa característica sofistica sua operacionalização e demonstra que é necessário um conjunto de prerrogativas e de provimentos para a efetivação do acesso ao mercado da alimentação escolar. Além da burocracia, o processo de compra e venda dos produtos da agricultura familiar no âmbito de mercados institucionais é complexo por envolver diversos tipos de ações relacionadas à potencialização da produção, processamento, distribuição e consumo de alimentos no município (WAGNER \& GEHLEN, 2015, p. 50).

No PNAE, a compra da agricultura familiar para a alimentação escolar cumpre um total de 10 etapas (Ver Manual "Aquisição de produtos da agricultura familiar para a alimentação escolar. $2^{a}$ edição - versão atualizada com a Resolução CD/FNDE no 04/2015”), que é iniciada com o 1) orçamento; 2) articulação entre os atores sociais; 3) elaboração do cardápio com base no potencial produtivo local; 4) pesquisa de preço; 5) chamada pública; 6) elaboração do projeto de venda, 7) recebimento e seleção dos projetos, 8) amostra de qualidade (quando necessário); 9) contrato de compra, finalizando com o 10) termo de recebimento e pagamento dos agricultores (FNDE, 2016).

No marco sanitário, situamos o $8^{\circ}$ passo que consiste na amostra de qualidade, ou seja, a Chamada Pública poderá prever a apresentação de amostras dos produtos a serem adquiridos junto à agricultura familiar e empreendimentos. Este passo é indicado apenas para produtos que dependam de habilitação sanitária nos termos da Resolução/RDC n 49, de 31 de outubro de 2013.

A legislação esclarece que produtos de origem vegetal in natura não necessitam de inspeção, mas caso estes produtos de origem vegetal venham a passar por algum tipo de processamento (a exemplo da farinha de mandioca, doce de rapadura feito de cana de açúcar, corante de urucum ou açafrão, temperos prontos, etc.) devem ser inspecionados e autorizados pelo órgão competente.

Já os produtos de origem animal (ovos, mel, leite, etc.), necessitam obrigatoriamente de inspeção sanitária das seguintes instâncias: "Serviço de Inspeção Municipal - SIM (permite a comercialização em âmbito municipal); Serviço de Inspeção Estadual - SIE (permite a comercialização em âmbito estadual); e Serviço de Inspeção Federal - SIF (permite a comercialização em todo território nacional)" (FNDE, 2016).

\section{Material e métodos}

A pesquisa partiu de um estudo qualitativo, descritivo, tipo estudo de caso. A técnica de coleta das informações utilizada foi à entrevista individual semiestruturada (áudio gravado). Para a definição dos sujeitos, foi realizado um levantamento do número total de agricultores familiares ativos no PNAE junto aos órgãos responsáveis pela gestão do programa (EMATER/MG e escolas), sendo um total de 14 (quatorze), na qual seis foram selecionados para participarem da pesquisa.

O estudo adotou como estratégia analítica a Análise de Conteúdo proposta por Bardin (2011), organizada em três fases, sendo elas: 1) a pré-análise; 2) a exploração do material e 3) o tratamento dos resultados, inferência e interpretação, na qual as análises das entrevistas áudio gravadas passaram pela leitura flutuante do material transcrito e destaque de trechos do texto (codificados) de acordo com o assunto abordado. A partir da realização de novas leituras, trechos referentes ao mesmo tema (código) foram aglutinados (categorizados), criando as categorias e subcategorias de análise referentes às entrevistas dos agricultores familiares.

A pesquisa se fez de acordo com a Resolução no 466 de 2012 da Comissão Nacional de Ética em Pesquisa do Ministério da Saúde, que define as normas éticas regulamentadoras de pesquisas envolvendo seres humanos (BRASIL, 2012), sendo aprovada pelo Comitê de Ética em Pesquisa (CEP) da Universidade Federal dos Vales do Jequitinhonha e Mucuri (UFVJM).

No presente trabalho, serão discutidos os principais pontos trazidos pelos entrevistados acerca da habilitação sanitária dos sistemas produtivos para o atendimento ao PNAE, conforme a categoria de análise a seguir.

\section{Resultados e discussão}

\section{Categoria: A adequação Sanitária dos sistemas produtivos para o atendimento ao PNAE em Ladainha MG}

Na pesquisa realizada constatamos que a regulamentação sanitária dos sistemas produtivos tem sido desafiadora para a participação dos agricultores familiares no PNAE. Ao passo que este marco regulatório reafirma o compromisso com a oferta qualificada dos alimentos para os escolares, torna-se empecilho para 
que alguns agricultores possam comercializar produtos como farinha de mandioca, corante, temperos, ovos, etc., ou até mesmo, possibilitar o ingresso de outros agricultores no programa.

Nosso interlocutor AF3 comercializa para a alimentação escolar via PNAE os seguintes alimentos: legumes, frutas e verduras, contudo, outros produtos que possui em seu sistema produtivo deixam de ser comercializados em virtude das questões de ordem sanitária conforme a fala abaixo:

Ovos eu tenho pra entregar, leite, farinha, mais não pode entregar por causa do laudo [Alvará sanitário]. Eu tenho um galpão e não posso tirar o corante para vender, um galpão que é uma seda [na linguagem popular do município, seda quer dizer que é zelado, limpol cê precisa de ver, galpão todo forrado, mais não deixa vender. Já tentei liberar, mais não deu, é difícil isso ai. Farinha eu não entrego e produzo, mandioca tá perdendo. A gente tem as coisas e não pode entregar, burocracia danada (AF3).

Com relação à oferta da alimentação escolar com segurança sanitária, o que pode ou não ser considerado burocrático? Com base na fala de outro agricultor familiar, podemos verificar que as questões sanitárias o impulsionou a investir em seu sistema produtivo, buscando adequá-lo as exigências sanitárias.

[...] quando tem a necessidade da habilitação sanitária eu sou motivado e obrigado a me adequar e ai eu vou tá ampliando minha estrutura física do meu local de produção, eu vou tá investindo em maquinários como eu tive que fazer empréstimos né, em máquinas novas, que são utensílios que precisa né (AF1).

Nosso entrevistado faz referência à estrutura de sua agroindústria familiar na qual relatou que "Tive que acessar os créditos através do PRONAF né" (AF1). Por meio desta fala, vemos a importância das políticas públicas para a agricultura familiar, sobretudo quando estas atuam de maneira complementar, sendo o Programa Nacional de Fortalecimento da Agricultura Familiar (PRONAF) um facilitador para as melhorias nas condições de produção e inclusão dos agricultores no mercado institucional através do PNAE e outros programas.

Neste sentido, dos seis sujeitos participantes da pesquisa, dois informaram que estão habilitados junto ao sistema de vigilância sanitária, comercializando para o PNAE através das agroindústrias familiares e relataram "já estou habilitado graças a Deus e já posso entregar [...] com o laudo de habilitação sanitária" (AF1), "Eu tenho minha agroindústria toda fiscalizada, tudo certinho" (AF4).

Dois Agricultores (AF3 e AF6) disseram que tentaram a habilitação e não conseguiram devido à burocracia e o alto custo financeiro que, para eles, não valeria a pena vista à quantidade de gêneros alimentícios que comercializam para as escolas.

Fazer o projeto fica caro demais entendeu. Tem essas dificuldades muito grande [...] Eu fiz o projeto das galinhas e comprei 200 pintadinha entendeu. Tive que disfazer de uma parte porque eu pensei numa quantidade de ovo maior pras escolas, caba daí, num pude entregar e tive que disfazer das pintadinhas [...] ai tinha que ter o laudo [...], fui saber do projeto [para habilitação sanitária]. A estrutura que [...] exige, a comparação não dá pra cobrir a produção de venda, a demanda que a gente tem (AF6).

Os outros dois Agricultores (AF2 e AF5) não manifestaram nenhuma inquietude visto que produzem alimentos de origem vegetal não processado.

Antes da Resolução/RDC n49/2013, duas possibilidades eram possíveis: Ou os agricultores familiares não comercializavam os produtos de origem vegetal processado ou de origem animal devido à falta do Alvará sanitário, ou ainda, comercializavam para a alimentação escolar sem a segurança sanitária necessária.

A partir do marco sanitário, as escolas municipais e estaduais do município de Ladainha passaram a exigir na Chamada Pública, dentre os documentos necessários, a apresentação do Alvará para os agricultores que comercializam alimentos processados.

Apesar de ser tido como fator de dificuldades para alguns, o objetivo do marco regulatório sanitário foi desburocratizar a produção e comercialização de tais produtos que necessitam de processamento e que são considerados como de baixo risco (art. $7^{\circ}$ da Resolução/RDC $\left.n^{\circ} 49 / 2013\right)$, a exemplo da produção artesanal de doces de rapadura de cana de açúcar, farina de mandioca, temperos, etc., pois, anterior a esta regulamentação, todos os sistemas de produção de alimentos eram submetidos a legislações mais rígidas da Agencia Nacional de Vigilância Sanitária (ANVISA), ainda que se configurassem como de baixo risco.

Neste sentido, a Resolução/RDC n ${ }^{\circ} 49 / 2013$ trás em seu art. $5^{\circ}$ as seguintes diretrizes: 
I - transparência dos procedimentos de regularização;

III - racionalização, simplificação e padronização dos procedimentos;

IV - integração e articulação a fim de evitar a duplicidade de exigências, na perspectiva do usuário;

V - proteção à produção artesanal a fim de preservar costumes, hábitos e conhecimentos tradicionais;

VI - razoabilidade quanto às exigências aplicadas (BRASIL, 2013).

Outros avanços do marco sanitário que visam desburocratizar o processo de habilitação podem ser verificados em seu art.12 $2^{\circ}$ que diz que os órgãos de vigilância sanitária poderão regularizar atividades instaladas em: "I- área desprovida de regulação fundiária legal ou com regulamentação precária; II residência; III - locais onde são realizadas as atividades produtivas dos empreendimentos” (BRASIL, 2013).

Trata-se de um grande avanço ao levarmos em consideração que muitos sistemas produtivos da agricultura familiar pertencem a comunidades assentadas da reforma agrária ou acampadas, também em terras não documentadas, em quitais das casas como ocorre em Ladainha, em que a agroindústrias familiares são instaladas no próprio terreiro das residências.

Contudo, na perspectiva dos agricultores familiares AF3 e AF6, participantes ativos do PNAE em Ladainha, na prática o marco sanitário não demonstra ser totalmente efetivo em virtude do alto custo narrado para a adequação dos sistemas produtivos. Apesar de serem atividades consideradas de baixo risco, existem obrigatoriedades nas instalações como: local de armazenar a matéria prima; local de transformação da matéria prima; armazenamento do produto final; embalagens; rótulos, etc., adequações que exigem, para além do apoio técnico da Empresa de Assistência Técnica e Extensão Rural (EMATER/MG), um investimento financeiro por parte dos agricultores.

Uma questão importante levantada na entrevista foi "Posso vender no mercado e não posso entregar nas escolas" (AF3). Trata-se de uma questão importante. O entrevistado relatou que os produtos que possui como temperos, ovos, farinha de mandioca, não podem ser comercializados para a alimentação escolar devido à ausência do Alvará Sanitário. Entretanto, relatou que comercializa a farinha de mandioca para as mercearias do município e as escolas vão até estas mercearias e compram tais farinhas que na verdade, foram produzidas pelo próprio agricultor.

Estas colocações nos levaram as seguintes questões: Ao adquirir um produto no comércio para a alimentação escolar, a gestão escolar não se preocupa em saber a procedência do alimento? O que justifica que um produto que não pode ser comprado diretamente com o agricultor familiar, mas tal produto do agricultor familiar ainda que sem o Alvará Sanitário, ao ser vendido para o comércio local, pode ser adquirido pelas escolas para a alimentação escolar? São questões contraditórias que merecem ser objeto de um estudo aprofundado.

Enquanto que uns alegam que o investimento não compensa os valores pagos nos produtos da agricultura familiar, outros demonstram ter “personalidade empreendedora”, utilizando a política de crédito para tornarem suas agroindústrias aptas pela inspeção sanitária (a exemplo do relato de AF1).

Durante a conversa sobre o investimento que precisou fazer em sua agroindústria familiar, AF1 nos disse "no momento eu não posso dizer que eu to ainda tirando lucro, mais só deu já ter garantido esse trabalho, já é um retorno”. Este agricultor demonstrou compreender que o investimento realizado proporcionará retorno financeiro a médio ou até longo prazo, abrindo possibilidades de comercializar tanto para o PNAE e Programa de Aquisição de Alimentos (PAA) ou até mesmos para os comércios tradicionais por portar o Alvará de Inspeção Sanitária.

Já nosso entrevistado AF3 que relatou ter produtos de origem animal e vegetal processados (ovos, farinhas e corantes feitos a partir do urucum), na qual não pode comercializar tais produtos ao PNAE por não dispor do Alvará Sanitário, ao ser questionado sobre a possibilidade de acessar a política de crédito rural e investir na adequação de sua estrutura de produção, relatou o seguinte: “Já me ofereceram PRONAF, mais eu não quis, tenho medo de fazer e não garantir, e não dar conta e sujar meu nome [...] eu já trabalho muito, fico com medo de fazer e não garantir. A gente tem que por o chapéu onde a mão alcança”.

Neste sentido, verificamos que ainda há resistência e insegurança por parte de alguns agricultores quanto ao acesso ao programa de crédito rural, destinado para o investimento e custeio de melhorias nos sistemas de produção agrícola.

AF1 nos contou que a periodicidade da inspeção sanitária geralmente é anual, pois o Alvará precisa ser renovado. No caso das agroindústrias, estas recebem inspeção municipal e da vigilância regional do Estado que são responsáveis por emitir o Alvará Sanitário: “[...] a visita da vigilância, às vezes eles chega assim sem esperar, a gente sabe que eles tão no município e vem né” (AF1). 
Ademais, AF4 afirmou "[...] a vigilância sanitária exige muito da gente, porque tem que ser transportando em um carro fechado e é o certo né”. Neste sentido, o agricultor familiar, apesar das dificuldades para se habilitar, têm a percepção de que tais exigências são necessárias e correspondem ao compromisso de se ter uma produção de alimentos com qualidade sanitária garantida.

No caso dos agricultores familiares que participam do PNAE em Ladainha, tivemos o exemplo de duas agroindústrias autorizadas via inspeção sanitária, uma realizando a entrega de pães e a outra, doce de rapadura feito a partir da cana de açúcar para as escolas.

Partindo da análise desta categoria, os agricultores ressaltaram que há uma orientação técnica da vigilância municipal e regional acerca da legislação sanitária para a adequação dos sistemas produtivos, sobretudo para os que possuem agroindústria familiar comercializando junto ao PNAE. Embora existam dificuldades, os agricultores reconhecem a importância deste marco para a alimentação escolar e para a agricultura familiar local.

\section{Conclusão}

Concluímos que a Resolução/RDC n49/2013 tratou de harmonizar os procedimentos de inclusão produtiva com segurança sanitária dos alimentos comercializados pelos agricultores familiares para o PNAE, garantindo aos escolares uma alimentação segura e qualificada.

Verificamos que as adequações sanitárias são entendidas como fator de dificuldades para o acesso e comercialização de alguns agricultores, fazendo com que estes não participem ou encerrem a participação no programa. Isto porque alegam que muitas das vezes as exigências para adequação dos sistemas produtivos são custosas financeiramente. Por outro lado, os agricultores que estão habilitados, ressaltaram que as adequações contribuem na confiabilidade dos alimentos destinados ao consumo dos escolares no município.

\section{Referências}

Bardin, L. 2011. Análise de Conteúdo (1a ed.). São Paulo, SP: Revista e Atualizada.

Brasil. 2009. Lei $\mathrm{n}^{\circ}$ 11.947, de 16 de Junho de 2009. Dispõe sobre o atendimento da alimentação escolar e do Programa Dinheiro Direto na Escola aos alunos da educação básica. Disponível em: <https://rebrae.com.br/wp-content/uploads/2017/05/Caderno deLegisla\%C3\%A7\%C3\%A3o-_FNDE_CECANE-UFRGS-_-2017.pdf >. Acesso em: 19 set. 2018.

Brasil. 2012. Resolução no 466, de 12 de Dezembro de 2012. Define as normas éticas regulamentadoras de pesquisas envolvendo heres humanos. Disponível <https://conselho.saude.gov.br/resolucoes/2012/Reso466.pdf> Acesso em: Acesso em: 18 jul. 2018.

Brasil. 2013. Resolução-RDC $n^{\circ} 49$, de 31 de Outubro de 2013 que dispõe sobre a regularização para o exercício de atividade de interesse sanitário do microempreendedor individual, do empreendimento familiar rural e do empreendimento econômico solidário e dá outras providências. Disponível em: <http://bvsms.saude.gov.br/bvs/saudelegis/anvisa/2013/rdc0049_31_10_2013.html> Acesso em: 16 out. 2018.

Fundo Nacional de Desenvolvimento da Educação [FNDE]. 2016. Agricultura familiar: Aquisição de produtos da agricultura familiar para o programa nacional de alimentação escolar. $2^{\text {a }}$ edição - versão atualizada com a Resolução CD/FNDE $n^{\circ}$ 04/2015. Brasília, 2016. Disponível em: <https:/www.fnde.gov.br/programas/alimentacao-escolar/alimentacao-escolar-material-dedivulgacao/alimentacao-manuais/item/8595-manual-de aquisi\%C3\%A7\%C3\%A3o-de-produtos-daagricultura-familiar-para-a-alimenta\%C3\%A7\%C3\%A3o-escolar> Acesso em: 10 jul. 2018.

Santos, A. J. S. 2017. Um programa, contextos distintos: um estudo sobre o PNAE no Território do Alto Jequitinhonha. Dissertação (Mestrado em Sociedade, Ambiente e Território), Montes Claros, MG: Universidade Federal de Minas Gerais.

Wagner, D., \& Gehlen, I. 2015. A inserção da Agricultura Familiar no mercado institucional: entre o direito e o acesso ao recurso da política pública. Revista Tempo da Ciência, 22(43). 


\section{Minicurrículo}

Mariane Rodrigues Silva. Bacharela em Serviço Social e Mestra em Estudos Rurais pela Universidade Federal dos Vales do Jequitinhonha e Mucuri (PPGER/UFVJM). Especialista em Gestão em Serviço Social pela Faculdade Batista de Minas. Teófilo Otoni, Minas Gerais - Brasil.

Nadja Maria Gomes Murta. Doutora em Ciências Sociais: Antropologia (PUC/SP); Docente do curso de Nutrição e dos Programas de Pós-Graduação Interdisciplinares em Estudos Rurais (PPGER) e Saúde, Sociedade e Ambiente (SASA) da Universidade Federal dos Vales do Jequitinhonha e Mucuri (UFVJM). Diamantina, Minas Gerais - Brasil.

Como citar: Silva, M.R., \& Murta, N.M.G. 2020. O marco sanitário na alimentação escolar: um estudo dos agricultores participantes do PNAE em Ladainha/MG. Pubsaúde, 3, a027. DOI: https:// dx.doi.org/10.31533/pubsaude3.a027

Recebido: 28 mar. 2020.

Revisado e aceito: 31 mar. 2020.

Conflito de interesse: os autores declaram, em relação aos produtos e companhias descritos nesse artigo, não ter interesses associativos, comerciais, de propriedade ou financeiros que representem conflito de interesse.

Licenciamento: Este artigo é publicado na modalidade Acesso Aberto sob a licença Creative Commons Atribuição 4.0 (CC-BY 4.0). 